\title{
Analysis on Setting of Animated Characters Modeling in Accordance with National Traditional Culture
}

\author{
Juan Wang \\ Huanghe Science and Technology College \\ Zhengzhou, China
}

\begin{abstract}
Every animation works will be influenced by factors such as nationality and culture of creator no matter what its theme and style is, and then reflect national characteristics in character personality, thought, action, speech, scene, props and even main idea. Every animation is carried with culture brand of the nationality more or less. National traditional culture possesses distinctive national characteristics, expression techniques; its peculiar cultural connotation development forms animation modeling with regional and national characteristics. Figure and animal images in animation of many countries mostly come from myth, fables and folklore and other excellent traditional culture of their own countries or nations which show unique artistic charm.
\end{abstract}

Keywords—character modeling; traditional; accordant points

\section{INTRODUCTION}

Setting of animated character modeling is one very important link in animation production, production quality and cost is closely linked with animation modeling design. To make one TV animation with standard length of 22 minutes needs to draw 8-12 pages of original animation every second at least and about 8,000-16,000 animation totally, so the workload is very large. If detail setting of animation modeling design is too complicated and modeling lines are too many, technology requirements for original animation will be higher and work strength will be larger and production time will be longer, then human cost and capital cost for animation will be increased a lot. Therefore, setting of animated character modeling requires rich artistic imagination; whether action conception, expression design or specified modeling environment must be refined, generalized and exaggerated on the basis of reality and characters shall be shaped through art recreation and association. For creation design of non-natural image, imagination is required more which has been widely applied in ancient painting art works. Flying Apsaras and Rebound Lute of Dunhuang Frescoes, Chaoyuan Map of the Yongle Palace Murals and Guanxiu's Lohan painting in Five Dynasties and so on all give full play to imagination and creativity of the artists.

\section{INFLUENCE OF CHINESE TRADITIONAL PAINTING ON CHINESE ANIMATION}

Chinese excellent traditional culture gives distinctive national characteristics to Chinese animation and adds cultural connotation for our animation development and make animation full of national characteristics. Many early Chinese animations are made referring to Chinese traditional New Year paintings and ancient temple murals techniques, such as The Proud General, Magic Brush and A Deer of Nine Colors, etc. Modeling design Sun Wukong in the first animated feature film Princess Iron Fan in China borrows Peking opera facebook pattern factors and national decoration. Golden Conch is one paper-cut animation "Fig. 1 ", but figures and backgrounds in the film show modeling characteristics of traditional shadow play clearly. Especially face, eyes and eyebrows of figures are connected. Also modeling of joints, cuffs, hair styles and trouser legs all come from modeling law of shadow play. Although the animation borrows shadow play in modeling and style, in order to facilitate posing of animation, much modeling improvement is done: 1. Modeling generalization, lines in face is softer than shadow play modeling's. 2. Proportion of hands and feet is magnified obviously, more uniform and in accordance with public aesthetics. 3. Simplify complicated decorative patterns of shadow play modeling. 4 . The colors are livelier, suitable for watch psychology of children.

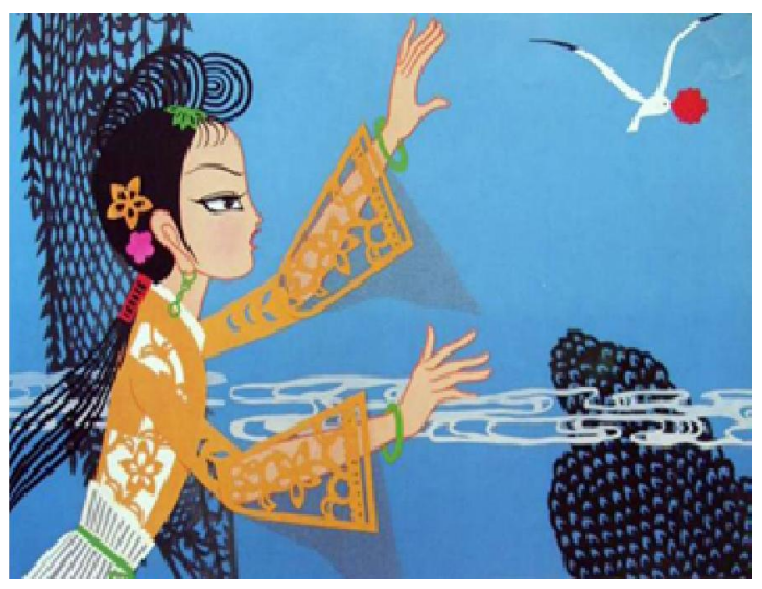

Fig. 1. Golden Conch 
Early ink and wash animation The Tadpoles Look For Their Mommy, Reed Pipe and ink and wash animation, Feeling from Mountain and Water, made by threedimensional software in recent years adopt Chinese traditional ink and wash painting techniques, develop effect of ink shade and virtuality and reality, take freehand as the principal theme and accurately and vividly reflect essence of Chinese traditional aesthetics and simple artistic style through special techniques. In these ink and wash animations, the audience does not only can enjoy wonderful animation plots, but also can feel one animation scene with fantastic ink and wash and infinite poetry. This type of animations takes advantages to express emotions, blended with feeling and scenery, reality in virtuality, virtuality in reality, combined with virtuality and reality, which shows deep charm of Chinese art.

\section{SETTING OF CHARACTER MODELING UNDER AESTHETIC CHARACTERISTICS OF CHINESE TRADITIONAL CUlture}

Along with development of science and technology and medium means in post-industrial era, animations do not only form one independent cultural form, but also becomes cultural representation of post-industrial era since 1990s; its influence is also gradually expanded. In Benjamin's view, relationship between human and traditional art changes after entering culture industry era. In the past, people always kept distance with traditional art categories, which was appreciation with fixed attention. However, as one representative of creational modern art, film dispels distance between human and works and makes people immersed in it. Therefore, we can say that contemporary animation relying on technology more changes this relationship further; fantasy atmosphere and game participation of animation completely pulls the audience to imaginary aesthetic time and space unrelated to the reality. In this sense, in the current life world, exaggeration and deformation techniques of animated character modeling is just as one bridge leading the audience thought. The other shore of the bridge is beautiful world with animation spirit provided by technology and based on optical image.

\section{A. From General Rules of Artistic Creation, Exaggeration and DeformationiIs Specific Expression of "Defamiliarization" Art Law}

Aristotle is one philosopher who has made earliest argument for aesthetic novelty in western literature and art aesthetics history. He emphasizes in Rhetoric that unusual atmosphere shall be given to usual things and unusual singularity shall be changed from familiar things to make the audience acquire amazing pleasure. From the perspective of animation image modeling, defamiliarization task lies in eliminating and deconstructing "previousness" expected by the audience and providing the optical image of "resistance" or "vividness" to motivate the audience's novelty feeling and unique experience for animation image.

In animated character modeling design, design creation techniques such as the most common exaggeration, deformation, comparison and combination are to highlight characteristics of animated characters, strengthen ornamental value, entertainment and humor sense and then strengthen artistic appeal and beauty of animation. Because of image features of animation and movement character of mobility, natural alienation originally exists between artistic effect shown in animation and reality. Therefore, in the aesthetic process, animation realizes defamiliarization effect inherently.

\section{B. From the Perspective of Realistic Feasibility of Animation Medium, Exaggeration and Deformation is Important Characteristics of Animation Aesthetics}

Although live action film can reach expression of exaggeration and deformation in virtue of digital technique, the cost is extremely expensive; meanwhile, because it origins form imagination of true life, issue of life logic and authenticity also becomes some restriction of visual spectacle. However, for animation production, we don't consider additional cost caused by this expression at all, only completing imagination visualization as if other procedures is ok. Therefore, we can realize exaggeration and deformation at will without considering authenticity of life logic in the expression, which is unique advantage of nonreal situation for animation accepted by the audience and assumed in advance. Hence, technical features of animation media does not only allow but supports the realization of visual spectacle with great feasibility. Exaggeration and deformation image modeling art also becomes important expression means of animation art naturally.

\section{From the Perspective of Acceptance Psychology for Animation, Exaggeration and Deformation not only Conforms to People'S Expectation for Wonderful Scene, but also Meets People'S Original Desire to Break Through Their Physiological Limit.}

The reason why the audience always have keen interest for flying, invisibility, deformation and mighty and other superman spectacular image is that deficiency of human's body and physical ability can cause certain inferiority feeling and motivate the desire of acquiring stronger power. This inferiority feeling and acquisition desire promotes the audience to get corresponding surpassing and compensation in the emotion through watching spectacular image. Just as some scholars say, affirmation for the audience's ego strength and body liberation in animation is realized by surpassing and overturn of animated character. Surpassing and overturn takes rational reality as object. The rational reality is constraint and restraint for ego strength, is non-free and non-perceptual.

In the exaggerated and deformed animation image modeling, some pictures of American animation such as Mickey Mouse and Donald Duck and Tom and Jerry have become classic; human or animal is crushed into flat paper, the belly is expanded into big balloon and the neck rotates 360 degrees like eraser, etc. In addition, this exaggeration and deformation is also very common in Japanese animation, such as Hayao Miyazaki's animation and animation series. Animation images with extremely huge volume frequently 
appear in One Piece and Naruto. However, what's the inherent theoretical foundation of this expression means?

Different from literary imagination, animation expression is intuitive, so uniqueness of fantasy and exaggeration become ontology characteristics of animation. If all spectacular images can motivate human's curiosity and mixoscopia, then exaggeration and deformation of human's physiological ability even conquer the audience mentally. Therefore, in this sense, whether to surpass and overturn rational reality even is one important standard to judge whether one animation has the ontology sprit. True, good and beautiful world with dream and spirituality conveyed by blue sky, white cloud, green grass, young girl and flying and other images in Hayao Miyazaki's animation completely constitutes one artistic conception surpassing earthliness and pointing to infiniteness. Although many American animations abide by business operating mode of mass culture products, rich humanistic care shown through plots, character's mental activity and dialogue, so they also can reach advanced stage of aesthetic awareness. Excellent literary works always reach the same goal through different means, however, creating exclusive artistic conception of Chinese culture under the guidance of artistic conception aesthetic theory is important way for Chinese animation to get rid of old style of imitation and improve art quality.

\section{CREATION SOURCE OF CURRENT CHINESE ANIMATION}

All in all, artistic creation conforms to the creation principle of originating from life but higher than life. Animation creation as highly assumptive art is even more so. Some animated characters are created by human and not exist in reality. For example, modeling of "kylin" "fig. 2", as specific magical mascot in Chinese traditional culture, "kylin" is the representative of Chinese traditional beauty culture. "kylin" modeling is the image combined with some beautiful and lucky and the most wonderful animal parts by people's gradual summarization of worship and cognition for nature in long-term life. In this way, some supernatural animation modelings always create surrealistic and brandnew visual fantasy feeling. This type of animation modeling creation does not only different from reality image, but also is closely linked with reality image. Moreover, it is the recreation borrowing reality image and cognitive thinking, reapplication of exaggeration and deformation under aesthetic characteristics. Therefore, sometimes the audience will feel this modeling familiar but novel and strange when they see it.

No animation films can reflect Chinese traditional culture characteristics enough in recent thirty years since early Chinese animations such as Havoc in Heaven, Nezha Conquers The Dragon King, A Daoist From Lao Mountain with distinct national style disappeared except for A Chinese Ghost Story: The Tsui Hark Animation, Even if annual output of animation TV play ranks first in the world this year, the situation is also awkward. However, Chinese audience find an entirely new world in A Chinese Ghost Story: The
Tsui Hark Animation, which can create pride sense for national culture.

A Chinese Ghost Story: The Tsui Hark Animation is Hong Kong animation works not released in mainland, however, its success is certain to bring good revelation for mainland animation. Although director of this animation is not Tsui Hark, Tsui Hark is screenwriter and producer, so many people owe this successful animation works to Tsui Hark. Perhaps because Tsui Hark is always one super animation fans, he shoots the story based on Strange Stories From A Chinese Studio vividly, with modern flavor and full of humor sense. Images of Ning Caichen and Nie Xiaoqian in A Chinese Ghost Story: The Tsui Hark Animation are with Chinese style, but the characters are more lovely and beautiful than traditional animations. Image of Yan Chixia looks like Zhong Kui but the form also resembles the actor, $\mathrm{Wu} \mathrm{Ma}$, who played the role of Yan Chixia in 1987 Hong Kong film A Chinese Ghost Story. This is common means and strategy of animations or games design in recent years, that is, take some real person (usually star) as model to design character image, then on the basis of it, make proper exaggeration and deformation (such as god Erlang in Lotus Lantern is design and modified according to Jiang Wen's image) and pursue vivid effect or star effect.

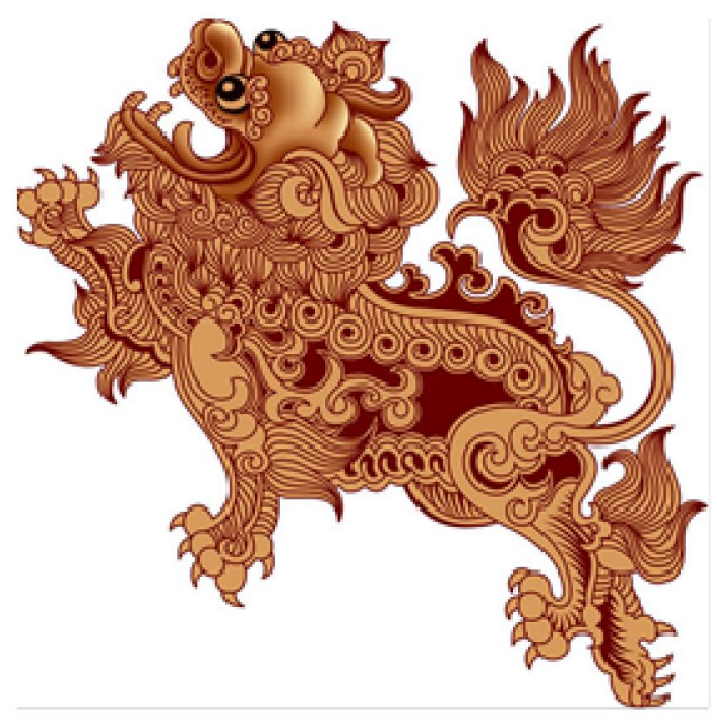

Fig. 2. Kylin

\section{CONCLUSION}

The artists launch practical exploration bravely under the creation thought programs of taking nationalization road, digging the national characteristics and inheriting and developing own art context. We can learn various existing forms, methods, techniques, images and colors in traditional culture elements including New Year wood-block print, paper-cut, shadow play, drama, figure stone, carving in Chinese painting and folk art. In recent years, some domestic animation companies, scientific research teams in colleges and universities also devote themselves to research of animation modeling design and original animation and strive to reflect the romantic charm of Chinese traditional culture; 
some industry delegates combine three dimensional animation technology and two-dimensional ink and wash animation language to make new language exploration of animation form. The key of continuous charm of animation is to research and borrow forms of traditional culture elements and color language and to combine them with modern design philosophy, to endow national cultural characteristics and time feature, to explore style diversification and modeling typification and to mould character modeling unifying form and sprit.

\section{REFERENCES}

[1] Yang Xiaolin. Analysis of Famous Animation Films in The World [M].Beijing: Communication University of China Press,2009:4-30.

[2] Xiao Ou, Zhang Tianxiao, Shu Xiao. Animation Layout [M].Beijing: China Machine Press, 20103-50.

[3] Meng Jun. Audio-Visual Language of Animation Films [M].Hubei: Hubei Fine Arts Publishing House, 2009:20-65.

[4] Ge Yuqing. Communications in the Virtual World: Animation Films and Intercultural Communication [M].Beijing: Communication University of China Press, 2011:15-35.

[5] Zhu Qi. New Art History and Visual Narrative [M].Hunan: Hunan Fine Arts Publishing House, 2009-55. 